\title{
Investigation and optimization of surface roughness with experimental design methods by turning of AISI-1050 after spheroidization heat treatment
}

\author{
Şehmus Baday ${ }^{1}$ (D) Hüdayim Başak ${ }^{2}$ (I) $\cdot$ Fikret Sönmez $^{3}$ (D)
}

Received: 20 July 2020 / Accepted: 24 November 2020 / Published online: 28 November 2020

(c) Springer Nature Switzerland AG 2020

\begin{abstract}
In this study, surface roughness values that were obtained by turning a medium-carbon steel (AISI 1050) applied to spheroidization heat treatment were modeled with two different optimization methods. The test materials were subjected to spheroidization heat treatment for three different periods as 15,60, and $180 \mathrm{~min}$. Three different cutting speeds and three different feed rates were used for the turning operations. Surface roughness values obtained from the surface of the workpieces after turning were analyzed by the response surface method (RSM) and Taguchi method (TM). These analyses show that the surface roughness changes directly depending on the feed rate and other parameters have a limited effect on the surface roughness. The regression analysis revealed that in both methods, the $R^{2}$ values were higher than 0.99, and it showed the effectiveness of these two methods. As a result, these two different experimental design methods showed high stability in solving this engineering problem. Additionally, in the comparison of the methods with each other, the ratio of similarity to the experimental results was evaluated by considering the percentage. The ratio of similarity was obtained by over $90 \%$ in both methods. When the ratio of similarity was analyzed, RSM had more effective results than TM.
\end{abstract}

Keywords Surface roughness · Taguchi method $\cdot$ Response surface method $\cdot$ Spheroidization heat treatment

\section{Introduction}

Metals are subjected to various heat treatments by a series of heating and cooling processes in order to obtain the required mechanical properties, hardness, and grain structures. The spheroidization heat treatment of highand medium-carbon steels is aimed to obtain spherical grains in the microstructure of the material. After the spheroidization heat treatment, machinability of the materials increases and cutting tool wear decreases, contributes to the total production by reducing the machining time of the workpiece and thus decreases the workpiece production costs. In machining processes, the aim is to ensure that the workpieces are in the desired surface quality and accurate dimensions.

In general, it is desirable to reduce the surface roughness of the workpieces to be manufactured in machining operations. Therefore, it is important to determine the cutting parameters affecting surface roughness [1, 2]. Many studies have been carried out on surface roughness, and such studies are still ongoing to achieve better results. In order to achieve these circumstances, the cutting parameters must be at the optimum values [3]. This is directly related to the optimization of the selected cutting parameters (cutting speed, feed rate, depth of cut, etc.) in the experiments $[4,5]$. Ozturk [6] focused on the surface

$\triangle$ Fikret Sönmez, sonmezfikret@gmail.com | ${ }^{1}$ Department of Mechanical and Manufacturing Engineering, Faculty of Technology, Batman University, Batman, Turkey. ${ }^{2}$ Department of Industrial Design Engineering, Faculty of Technology, Gazi University, Ankara, Turkey. ${ }^{3}$ Department of Mechanical Engineering, Hasan Ferdi Turgutlu Faculty of Technology, Manisa Celal Bayar University, Manisa, Turkey. 
roughness of the AA7075 material in turning operations using carbide inserts. The Taguchi method and ANOVA were used to evaluate the cutting parameters. The study revealed that feed rate affects the surface quality more than the other parameters (the depth of cut and cutting speed). In the study by KIvak [7], Hadfield steel was applied to a turning operation using coated inserts (PVD and CVD). The surface roughness and insert wear values were optimized with the Taguchi method $\left(\mathrm{L}_{18}\right)$. As a result, it was found that the feed rate on the surface roughness and cutting speed in tool wear were the most effective parameters. Ribeiro et al. [8] used the optimization of machining parameters to improve surface quality. The Taguchi orthogonal method $\left(\mathrm{L}_{16}\right)$ was used in the optimization process. The ANOVA test results revealed that the radial cutting depth was the most effective parameter (30\%), and the interaction between the radial and axial depth of cut was in second place in terms of contribution (24\%) in this study. Awopetu et al. [9] investigated the effects of cutting parameters on the surface roughness of mild-carbon steel (AISI 1020) by using the Taguchi $\left(\mathrm{L}_{16}\right)$ method. The analysis showed that high cutting speed, low depth of cut, and low feed rates were suitable for obtaining low surface roughness. Verma et al. [10] used steel alloys to investigate turning parameters by the Taguchi $\left(\mathrm{L}_{9}\right)$ method. The results showed that cutting speed and feed rate were effective on surface roughness by about 57 and $23 \%$, respectively. Thamizhmanii et al. [11] analyzed the optimum cutting parameters to obtain lower surface roughness on the SCM 440 material with the Taguchi $\left(\mathrm{L}_{18}\right)$ method. The analysis showed that the depth of cut plays a significant role. Palanikumar [12] investigated surface roughness on fiber-reinforced plastic (GFRP) composites. The research was carried out with the Taguchi $\left(\mathrm{L}_{27}\right)$ method. Feed rate had a great effect on surface roughness. Salvi [13] adopted the Taguchi method on turning $20 \mathrm{MnCr} 5$ steel. The optimum cutting parameters were examined to obtain a lower surface roughness. The Taguchi approach showed that the feed rate was the most important parameter in the experiments. Sarikaya [14] estimated the surface roughness values obtained by turning stainless steel using a coolant with the Taguchi method. As a result of their study, they found that the feed rate was the parameter that was the most effective on surface roughness.

In the literature review, it was seen that many optimization methods were used besides the Taguchi method for surface roughness optimization. Sahoo [15] used not only the Taguchi method but also the response surface methodology to evaluate surface roughness. Sahoo examined surface roughness after the turning process using the optimization methods such as RSM and genetic algorithms. Muñoz-Escalona et al. [16] examined surface roughness on a face milling operation in the AA-7075 material. An artificial neural networks model was developed for the prediction of surface roughness values after a face milling operation. The Taguchi method was also used to reduce the number of experiments. The study showed that surface roughness was directly affected by chip thickness. Basmaci et al. [17] estimated surface roughness by using the Taguchi method and RSM. They examined the parameters that affected surface roughness in turning of material (Hastelloy C-22). They also carried out studies on the optimization of these cutting parameters. As a result, the most effective parameters for the lowest surface roughness, respectively, were cutting speed, entering angle, chip angle, and flow rate. Ekici et al. [18] optimized the surface roughness values obtained by turning Hadfield steel by RSM. As a result of their studies, they found that the parameter that was the most effective on surface roughness was the feed rate. Izule et al. [19] used the response surface method to optimize the vibration and surface roughness values obtained in turning the $41 \mathrm{Cr} 4$ alloy. The study showed that the RSM model accurately predicted surface roughness and vibration values. Kumar et al. [20] investigated the effects of cutting parameters in turning the AA7075 alloy. RSM and artificial neural networks were applied to analyze cutting parameters (cutting speed, feed rate, and approach angle). The study revealed that feed rate was the most effective parameter in experiments and had a more significant contribution to both materials than speed and approach angle.

In the literature, although the surface roughness values resulting from machining are analyzed with experimental design methods, two different experimental design methods (surface response method and the Taguchi method) were used in this study when analyzing the surface roughness values. Thus, the experimental design methods are compared with each other and the advantages and disadvantages offered by these methods are analyzed. Additionally, the effectiveness of the experimental design results was compared, and the best results were obtained.

\section{Materials and methods}

The AISI 1050 steels are medium-carbon steels with a carbon content of about $0.5 \%$ and are often used in a wide range of applications as a result of their high heat treatment suitability, good machinability, and a good combination of mechanical properties. For this reason, the AISI 1050 steel material was preferred in the studies and subjected to spheronization heat treatment at two different temperatures and three different times. The chemical composition of the AISI 1050 steel is given in Table 1.

The AISI 1050 workpieces were machined to the desired dimensions $(\varnothing 30 \times 200 \mathrm{~mm})$ to perform the tests. 
Table 1 Chemical composition of AISI 1050 steel

\begin{tabular}{llllll}
\hline $\mathrm{C}$ & $\mathrm{Mn}$ & $\mathrm{Si}$ & $\mathrm{P}$ & $\mathrm{S}$ & $\mathrm{Fe}$ \\
\hline $0.45-0.54$ & $0.60-0.90$ & $0.10-0.30$ & 0.009 & 0.022 & Remain \\
\hline
\end{tabular}

The prepared workpieces were austenitized at $850^{\circ} \mathrm{C}$ for $15 \mathrm{~min}$ before the spheroidization process, and subsequently, water quenching was applied to the materials. After all, the samples were subjected to three different spheronization times $(15,60$, and $180 \mathrm{~min}$.) and two different temperatures $\left(600^{\circ} \mathrm{C}\right.$ and $\left.700^{\circ} \mathrm{C}\right)$.

After all the heat treatment operations, in the machining process of the PSBNR 2525M12 form tool holder and the CVD-coated GC4215 form, double-sided cutting tools were selected. The SNMG 120,408 PM form chip breaker geometry was selected. For each workpiece, it was aimed to increase the validity of the experiment by using a new cutting tool.

A CNC lathe (TC-35 JOHNFORD) was used for the experiments. A $2.5 \mathrm{~mm}$ cutting depth was determined, and dry cutting was preferred during the process. A portable surface roughness tester (Mitutoyo Surftest SJ-201) was used to measure surface roughness values after the experiments. The mean surface roughness $(R a)$ values were used for surface roughness measurements.

In the analysis of surface roughness, the cutting speed and the feed rate parameters, which are frequently used in the literature [21], were examined. In addition to these parameters, the parameters of spheronization time and spheronization temperature were also used in the analysis. The experimental set and parameters created for this study are shown in Table 2.

Experimental design methods are systematic methods that allow results to be obtained with a smaller number of experiments for a determined experimental set. The Taguchi method (TM) is highly applicable to many machining processes [22, 23]. In some optimization studies, the response surface method (RSM) method is preferred [24]. Apart from these methods, many different optimization methods can be applied in machining [15]. Among these methods, the TM and the RSM were chosen

Table 2 Experimental set

\begin{tabular}{lcll}
\hline Parameters & & & \\
\hline Temp ${ }^{\circ} \mathrm{C}$ & Time min & $\begin{array}{l}\text { Cutting speed } \mathrm{mm} / \\
\text { min }\end{array}$ & $\begin{array}{l}\text { Feed } \\
\text { rate } \\
\mathrm{mm} / \mathrm{rev}\end{array}$ \\
\hline 600 & 15 & 150 & 0.16 \\
700 & 60 & 175 & 0.25 \\
& 180 & 200 & 0.4 \\
\hline
\end{tabular}

for the present study because of their good results in previous literature studies. Thus, the experimental sets generated by RSM and TM were used for the study. The Minitab program was preferred for the implementation and analysis of these two methods. In the experimental design, both analyses were performed for two spheroidization temperatures $\left(600^{\circ} \mathrm{C}\right.$ and $\left.700^{\circ} \mathrm{C}\right)$ separately.

Experimental design methods aim to achieve a result with a lower number of experiments with a sample subset from the whole experimental set. For the experimental sets processed at $600{ }^{\circ} \mathrm{C}$ and $700{ }^{\circ} \mathrm{C}$, a total of 27 tests $(3 \times 3 \times 3=27)$ were required if all of the experimental design parameters were used (Table 3 ). From the whole (27) experimental data, 15 experimental data were selected by RSM and nine experimental data were selected by TM. The selected experimental data for RSM and TM are shown in Table 4. The experimental data selected by both methods were different from each other except for two units of data.

Different models may be created by using RSM to solve engineering problems. The Box-Wilson and Box-Behnken models are mainly used in $\operatorname{RSM}[25,26]$. This study preferred the Box-Behnken model, which may be modeled with a smaller number of experiments. This model was selected as it allows multiple parameter changes at the same time for a single set of experiments.

The experimental design selected by RSM and the levels of these data are shown in Table 5. With this method, it is possible to evaluate the experimental set with a total of 15 experiments.

In the TM experimental design, modeling is performed according to the levels created for different parameters. Three parameters affecting surface roughness values were evaluated on three different levels. This experimental set consisting of 27 experiments could be evaluated by TM with a total of nine experiments $\left(L_{9}\right)$. The data used in the TM experimental design and their levels are shown in Table 6.

Table 3 Experimental design parameters

\begin{tabular}{|c|c|c|c|c|}
\hline \multicolumn{2}{|c|}{ Response surface method levels } & \multirow{3}{*}{$\begin{array}{l}\text { Level } 1 \\
\text { Level } 1\end{array}$} & \multirow{3}{*}{$\begin{array}{l}\text { Level } 0 \\
\text { Level } 2\end{array}$} & \multirow{3}{*}{$\begin{array}{l}\text { Level } 1 \\
\text { Level } 3\end{array}$} \\
\hline \multicolumn{2}{|c|}{ Taguchi method levels } & & & \\
\hline Symbol & Parameter & & & \\
\hline$t$ & Spheroidization time ( $\mathrm{min}$. ) & 15 & 60 & 180 \\
\hline$v$ & Cutting speed (m/min.) & 150 & 175 & 200 \\
\hline$f$ & Feed rate $(\mathrm{mm} / \mathrm{rev})$. & 0.16 & 0.25 & 0.40 \\
\hline
\end{tabular}


Table 4 Experimental data selected by two different experimental designs

\begin{tabular}{|c|c|c|c|c|}
\hline Exp. number & $\begin{array}{l}\text { Spheroidization } \\
\text { time (t) (min.) }\end{array}$ & $\begin{array}{l}\text { Cutting speed (v) } \\
\text { (m/min.) }\end{array}$ & $\begin{array}{l}\text { Feed rate }(\mathrm{f}) \\
(\mathrm{mm} / \mathrm{rev} .)\end{array}$ & $\begin{array}{l}\text { Design method in which } \\
\text { the data were selected }\end{array}$ \\
\hline 1 & 15 & 150 & 0.16 & Selected by TM \\
\hline 2 & 15 & 150 & 0.25 & Selected by RSM \\
\hline 3 & 15 & 150 & 0.4 & \\
\hline 4 & 15 & 175 & 0.16 & Selected by RSM \\
\hline 5 & 15 & 175 & 0.25 & Selected by TM \\
\hline 6 & 15 & 175 & 0.4 & \\
\hline 7 & 15 & 200 & 0.16 & \\
\hline 8 & 15 & 200 & 0.25 & Selected by RSM \\
\hline 9 & 15 & 200 & 0.4 & Selected by TM \\
\hline 10 & 60 & 150 & 0.16 & Selected by RSM \\
\hline 11 & 60 & 150 & 0.25 & Selected by TM \\
\hline 12 & 60 & 150 & 0.4 & Selected by RSM \\
\hline 13 & 60 & 175 & 0.16 & \\
\hline 14 & 60 & 175 & 0.25 & Selected by RSM \\
\hline 15 & 60 & 175 & 0.4 & Selected by TM \\
\hline 16 & 60 & 200 & 0.16 & Selected by RSM and TM \\
\hline 17 & 60 & 200 & 0.25 & \\
\hline 18 & 60 & 200 & 0.4 & Selected by RSM \\
\hline 19 & 180 & 150 & 0.16 & \\
\hline 20 & 180 & 150 & 0.25 & Selected by RSM \\
\hline 21 & 180 & 150 & 0.4 & Selected by TM \\
\hline 22 & 180 & 175 & 0.16 & Selected by TM \\
\hline 23 & 180 & 175 & 0.25 & \\
\hline 24 & 180 & 175 & 0.4 & Selected by RSM \\
\hline 25 & 180 & 200 & 0.16 & \\
\hline 26 & 180 & 200 & 0.25 & Selected by RSM and TM \\
\hline 27 & 180 & 200 & 0.4 & \\
\hline
\end{tabular}

Table 5 Experimental set using RSM

\begin{tabular}{|c|c|c|c|c|c|c|c|}
\hline \multirow[t]{2}{*}{ Exp. number } & \multicolumn{2}{|c|}{ Spheroidization time $(\mathrm{t})(\mathrm{min})}$. & \multicolumn{2}{|c|}{ Cutting speed (v) (m/min.) } & \multicolumn{2}{|c|}{ Feed rate $(f)(m m / r e v)}$. & \multirow{2}{*}{$\begin{array}{l}\text { Experimental results } \\
\text { surface roughness } \\
(\mu \mathrm{m})\end{array}$} \\
\hline & Level & Actual values & Level & Actual values & Level & Actual values & \\
\hline 1 & -1 & 15 & -1 & 150 & 0 & 0.25 & 1.98 \\
\hline 2 & 1 & 180 & -1 & 150 & 0 & 0.25 & 2.145 \\
\hline 3 & -1 & 15 & 1 & 200 & 0 & 0.25 & 2.000 \\
\hline 4 & 1 & 180 & 1 & 200 & 0 & 0.25 & 2.205 \\
\hline 5 & -1 & 15 & 0 & 175 & -1 & 0.16 & 1.24 \\
\hline 6 & 1 & 180 & 0 & 175 & -1 & 0.16 & 1.455 \\
\hline 7 & -1 & 15 & 0 & 175 & 1 & 0.40 & 6.185 \\
\hline 8 & 1 & 180 & 0 & 175 & 1 & 0.40 & 7.11 \\
\hline 9 & 0 & 60 & -1 & 150 & -1 & 0.16 & 1.065 \\
\hline 10 & 0 & 60 & 1 & 200 & -1 & 0.16 & 1.000 \\
\hline 11 & 0 & 60 & -1 & 150 & 1 & 0.40 & 6.67 \\
\hline 12 & 0 & 60 & 1 & 200 & 1 & 0.40 & 6.945 \\
\hline 13 & 0 & 60 & 0 & 175 & 0 & 0.25 & 2.365 \\
\hline 14 & 0 & 60 & 0 & 175 & 0 & 0.25 & 2.365 \\
\hline 15 & 0 & 60 & 0 & 175 & 0 & 0.25 & 2.365 \\
\hline
\end{tabular}


Table 6 Experimental set using TM

\begin{tabular}{|c|c|c|c|c|c|c|c|}
\hline \multirow[t]{2}{*}{ Exp. number } & \multicolumn{2}{|c|}{ Spheroidization time (t) (min.) } & \multicolumn{2}{|c|}{ Cutting speed $(\mathrm{v})(\mathrm{m} / \mathrm{min})}$. & \multicolumn{2}{|c|}{ Feed rate $(\mathrm{f})(\mathrm{mm} / \mathrm{rev})}$. & \multirow[b]{2}{*}{$\begin{array}{l}\text { Experimental results } \\
\text { surface roughness } \\
(\mu \mathrm{m})\end{array}$} \\
\hline & Level & Actual values & Level & Actual values & Level & Actual values & \\
\hline 1 & 1 & 15 & 1 & 150 & 1 & 0.16 & 0.765 \\
\hline 2 & 1 & 15 & 2 & 175 & 2 & 0.25 & 2.120 \\
\hline 3 & 1 & 15 & 3 & 200 & 3 & 0.40 & 6.000 \\
\hline 4 & 2 & 60 & 1 & 150 & 2 & 0.25 & 2.040 \\
\hline 5 & 2 & 60 & 2 & 175 & 3 & 0.40 & 6.860 \\
\hline 6 & 2 & 60 & 3 & 200 & 1 & 0.16 & 1.000 \\
\hline 7 & 3 & 180 & 1 & 150 & 3 & 0.40 & 6.950 \\
\hline 8 & 3 & 180 & 2 & 175 & 1 & 0.16 & 1.455 \\
\hline 9 & 3 & 180 & 3 & 200 & 2 & 0.25 & 2.205 \\
\hline
\end{tabular}

\section{Results and discussion}

After the experiments, the Minitab 17 package program was used for the evaluation of both RSM and TM. The experiments performed at $600^{\circ} \mathrm{C}$ and $700^{\circ} \mathrm{C}$ were modeled separately. In the modeling process using RSM, a first-degree (linear) model was preferred. This model is seen in Eq. 1. The back-propagation elimination was used to increase the prediction capability of the model generated with RSM:

$Y=\beta_{0}+\beta_{1} X_{1}+\beta_{2} X_{2}+\beta_{3} X_{3}$

The essential factor in TM is the signal-to-noise ratio. In the modeling of surface roughness values, it was desired to reach the smallest surface roughness value. Therefore, in the calculation of the signal-to-noise $(\mathrm{S} / \mathrm{N})$ ratio, the "smaller is better" formula was used. The formula is shown in Eq. 2:

$S / N=-10 x \log \left(\frac{\sum y^{2}}{n}\right)$

The result of the ANOVA generated by both models (RSM and TM) for the experiments performed at $600{ }^{\circ} \mathrm{C}$ can be seen in Table 7 (Fig. 1).
The high Adj. SS values in Table 7 show that the feed rate is the most effective parameter for both the RSM and the TM models. The effectiveness of other parameters is very low. This result was in parallel with several studies in the literature $[6,13,14,18]$. In order to better understand the effectiveness of the parameters, the \% effectiveness value was calculated and plotted for each parameter in both methods (Fig. 2).

In the activity plots shown in Fig. 2, the results of the two methods were very close to each other. The efficiency of the feed rate parameter was $100 \%$ in the RSM model and $98 \%$ in the TM model. The other two factors, namely the cutting speed and spheroidization time, had very low effectiveness. The ANOVA results generated by both models (RSM and TM) for the experiments performed at $700^{\circ} \mathrm{C}$ can be seen in Table 8

Similar to the results at $600^{\circ} \mathrm{C}$ in Table 7, although the statistical values calculated were different, the experimental parameters remained insensitive to temperature. The feed rate parameter was the most dominant. Figure 3 shows the plots of the effectiveness of the parameters.

When the results obtained in Fig. 3 were examined, similar to the results at $600{ }^{\circ} \mathrm{C}$, the efficiency of the feed rate parameter was $100 \%$ in the RSM model and $99 \%$ in the TM model. In all experiments, the cutting speed and spheroidization time parameters were almost ineffective.
Table 7 ANOVA models created for $600^{\circ} \mathrm{C}$ temperature

\begin{tabular}{|c|c|c|c|c|c|c|c|c|c|c|}
\hline \multirow[t]{2}{*}{ Source } & \multicolumn{2}{|l|}{ DOF } & \multicolumn{2}{|l|}{ Adj. SS } & \multicolumn{2}{|c|}{ Adj. MS } & \multicolumn{2}{|l|}{ F value } & \multicolumn{2}{|c|}{$P$ value } \\
\hline & RSM & TM & RSM & TM & RSM & TM & RSM & TM & RSM & TM \\
\hline Spheroidization time & 2 & 1 & 0.501 & 0.285 & 0.251 & 0.285 & 9.01 & 7.54 & 0.10 & 0.041 \\
\hline Cutting speed & 2 & 1 & 0.253 & 0.011 & 0.127 & 0.011 & 4.55 & 0.28 & 0.180 & 0.621 \\
\hline Feed rate & 2 & 1 & 51.77 & 61.33 & 25.88 & 61.33 & 930.9 & 1622.1 & 0.001 & 0.000 \\
\hline Error & 2 & & 0.056 & & 0.028 & & & & & \\
\hline Total & 8 & 3 & 52.58 & 61.62 & & & & & & \\
\hline
\end{tabular}




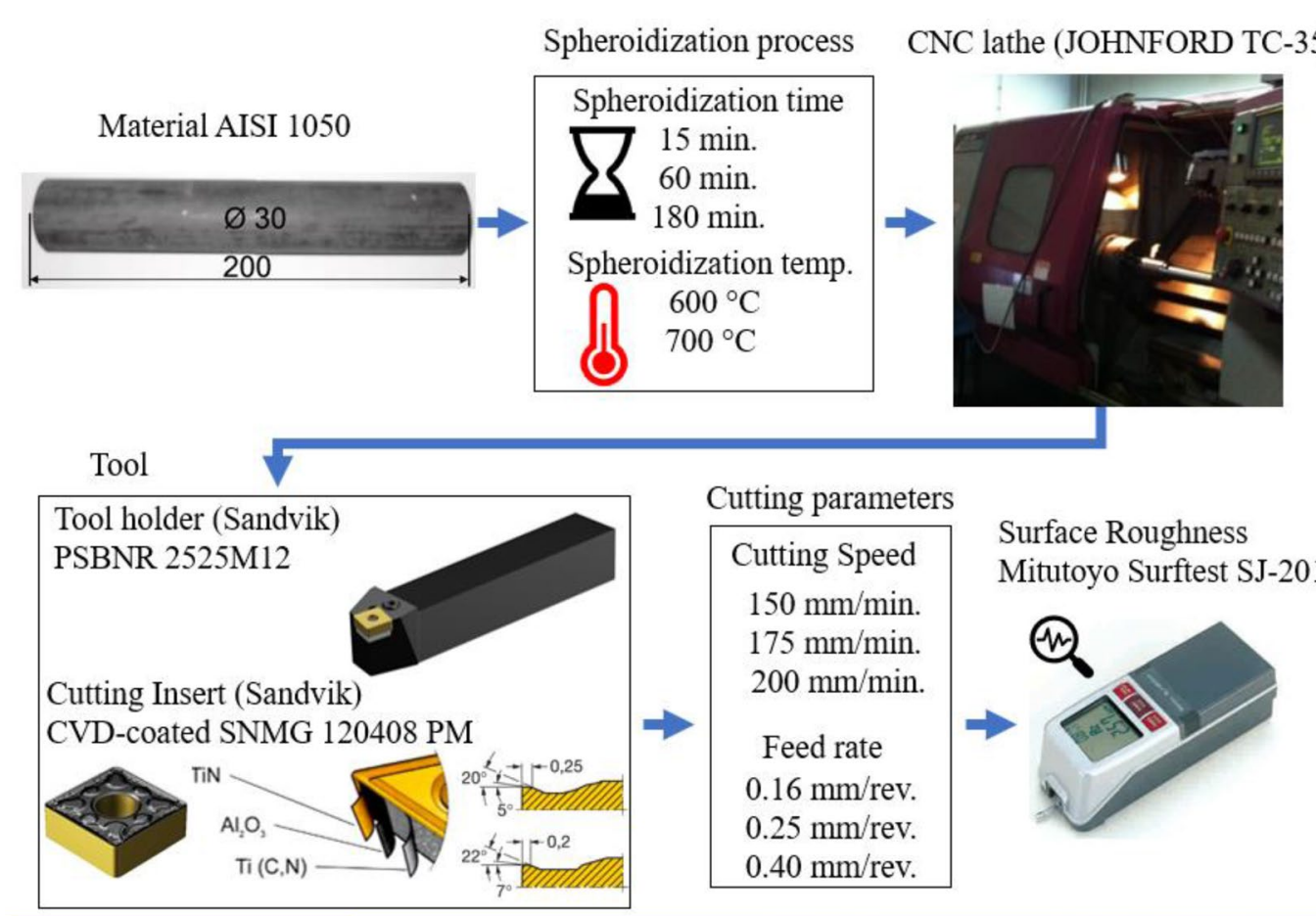

Fig. 1 Experiment order

EFFECTIVENESS OF PARAMETERS-RSM

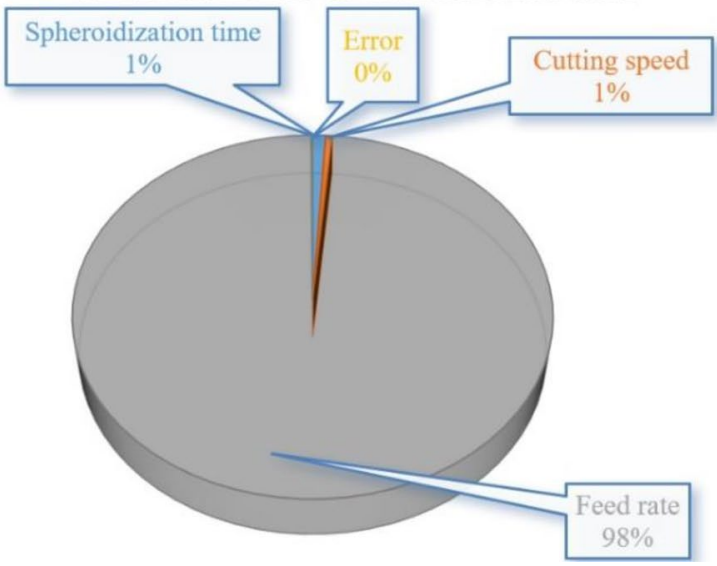

EFFECTIVENESS OF PARAMETERS-TM

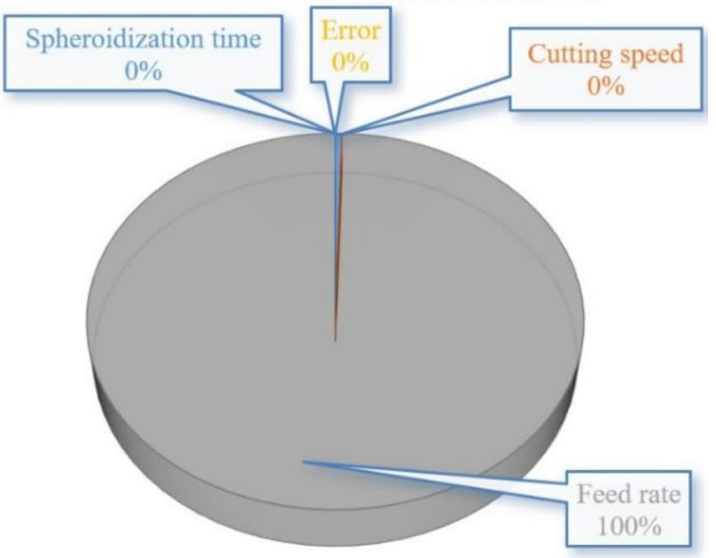

Fig. 2 Efficiency of parameters for experiments at $600^{\circ} \mathrm{C}$

Table 8 ANOVA models created for $700{ }^{\circ} \mathrm{C}$ temperature

\begin{tabular}{|c|c|c|c|c|c|c|c|c|c|c|}
\hline \multirow[t]{2}{*}{ Source } & \multicolumn{2}{|l|}{ DOF } & \multicolumn{2}{|l|}{ Adj. SS } & \multicolumn{2}{|l|}{ Adj. MS } & \multicolumn{2}{|l|}{ F-value } & \multicolumn{2}{|c|}{$P$ value } \\
\hline & RSM & TM & RSM & TM & RSM & TM & RSM & TM & RSM & TM \\
\hline Spheroidization time & 2 & 1 & 0.075 & 0.391 & 0.075 & 0.195 & 1.91 & 7.57 & 0.226 & 0.117 \\
\hline Cutting speed & 2 & 1 & 0.012 & 0.041 & 0.012 & 0.020 & 0.30 & 0.78 & 0.61 & 0.56 \\
\hline Feed rate & 2 & 1 & 65.57 & 58.89 & 65.57 & 29.45 & 1667.8 & 1141.1 & 0.00 & 0.001 \\
\hline Error & 2 & & & 0.052 & & 0.026 & & & & \\
\hline Total & 8 & 3 & 65.66 & 59.38 & & & & & & \\
\hline
\end{tabular}




\section{EFFECTIVENESS OF PARAMETERS- RSM}

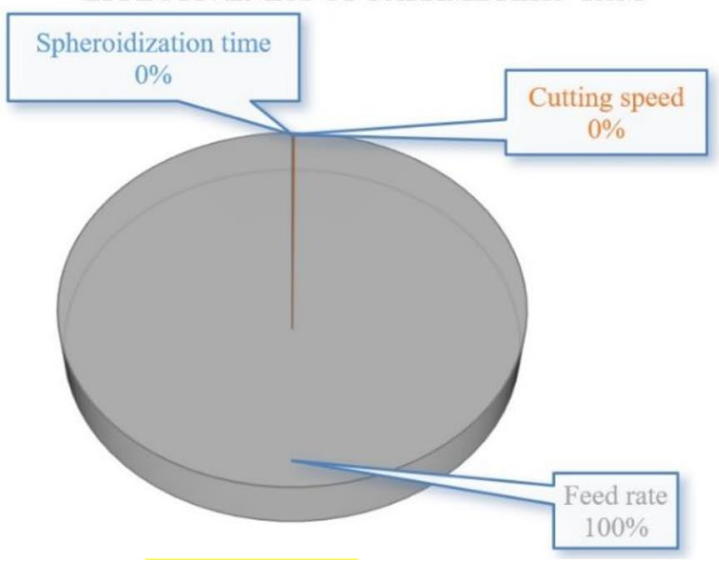

\section{EFFECTIVENESS OF PARAMETERS- TM}

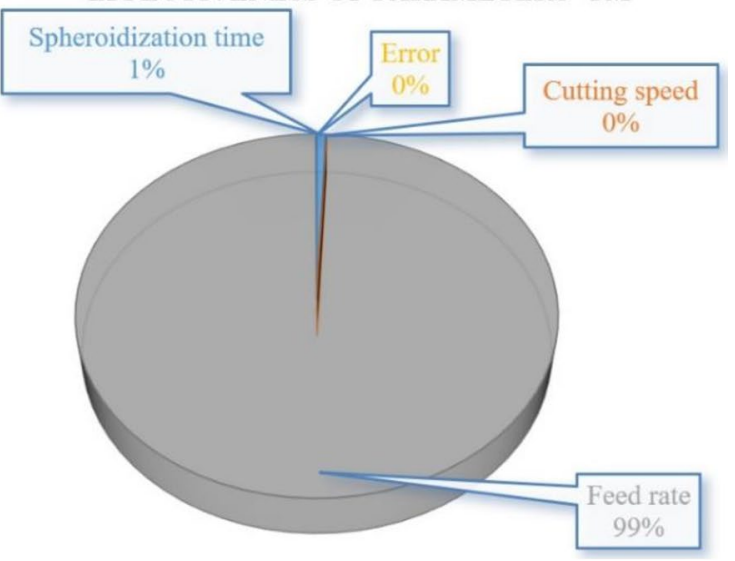

Fig. 3 Efficiency of parameters for experiments at $700{ }^{\circ} \mathrm{C}$

The main effect and signal-to-noise ratios of the experiments performed at a temperature of $600^{\circ} \mathrm{C}$ in the Taguchi experimental design are shown in Fig. 4.

It was observed that spheroidization time and cutting speed parameters had a particularly limited effect on both the main effect plot and signal-to-noise plot graph in Fig. 4. The feed rate had a significant effect. Increasing the feed rate significantly increased surface roughness (almost \% 500). Similar plots were formed in the experiments conducted at $700{ }^{\circ} \mathrm{C}$ in Fig. 5 .

The experiments conducted at $700{ }^{\circ} \mathrm{C}$ (Fig. 5) were almost identical to the experiments conducted at $600{ }^{\circ} \mathrm{C}$ (Fig. 4). In the plots shown in Fig. 5, the effectiveness of the parameters other than the feed rate parameter was very limited. This has shown that the temperature change in the spheroidization process is almost ineffective on surface roughness. The interactions of the parameters affecting surface roughness are shown in Fig. 6.

The plots formed as a result of the interaction of all parameters (Fig. 6). At both $600{ }^{\circ} \mathrm{C}$ and $700{ }^{\circ} \mathrm{C}$, the plots obtained as a result of the experiments were almost identical. These results showed that the effect of the temperature difference on the experimental results was quite limited. The spheroidization time and cutting speed parameters could not provide significant results. This may be explained by the fact that the parameters other than the feed rate were almost ineffective, as shown in the results of ANOVA.

After analyzing the relations of experimental parameters with each other using the Taguchi method, the relations of these experimental parameters with each other were also analyzed by RSM. The parameters that

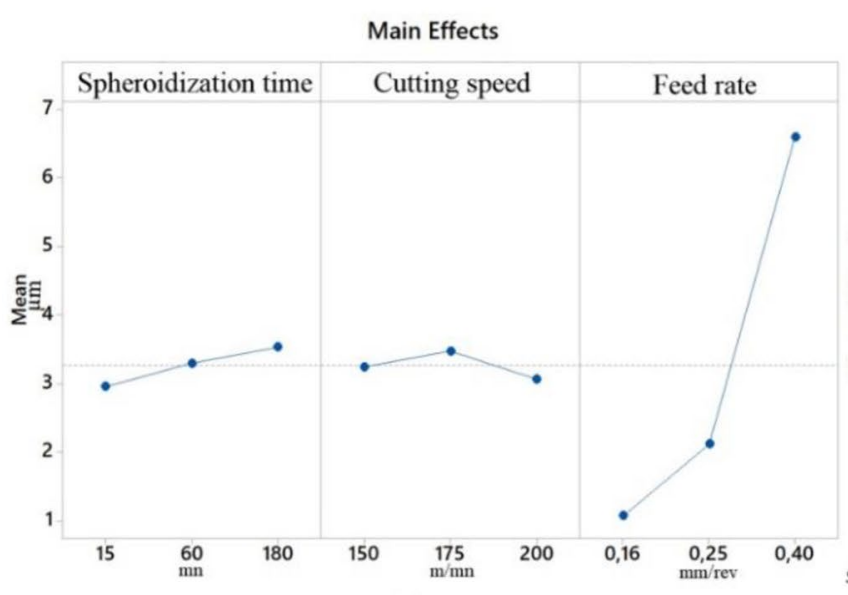

(a)

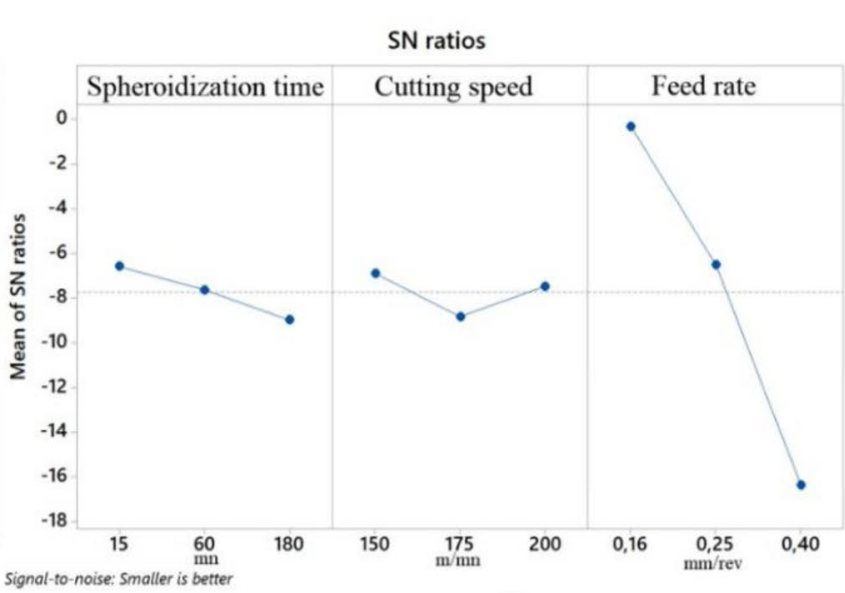

(b)

Fig. 4 Mean values of control factors for surface roughness results at $600^{\circ} \mathrm{C}$ a and $S / N$ ratios $\mathbf{b}$ 
affected the surface roughness values are divided into two groups $\left(600{ }^{\circ} \mathrm{C}\right.$ and $\left.700^{\circ} \mathrm{C}\right)$ and plotted in Figs. 7,8 , and 9 . First of all, the effects of spheroidization time and cutting speed parameters on the surface roughness are evaluated in Fig. 6.

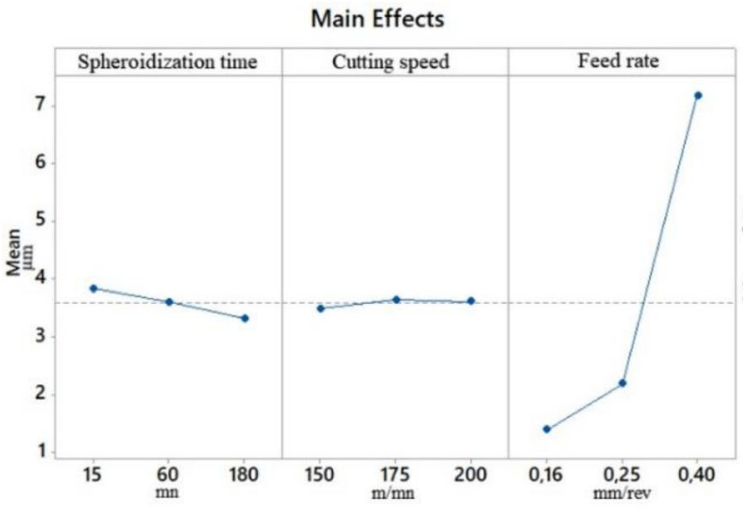

(a)

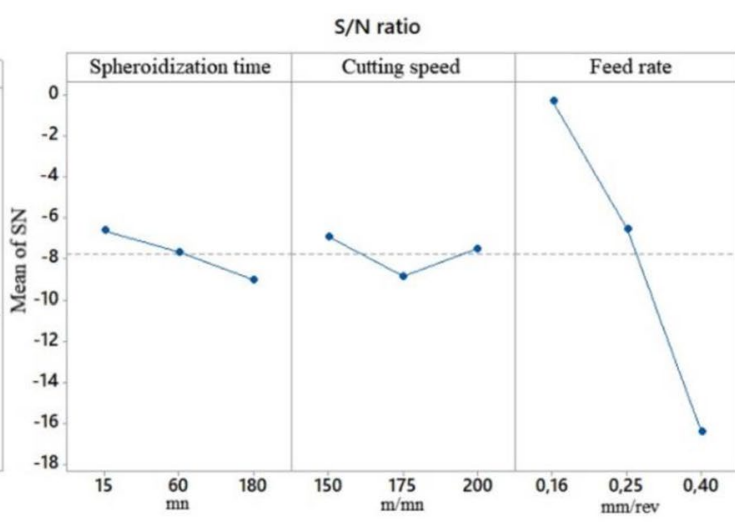

(b)

Fig. 5 Mean values of control factors for surface roughness results at $700^{\circ} \mathrm{C}$ a and $\mathrm{S} / \mathrm{N}$ ratios $\mathbf{b}$

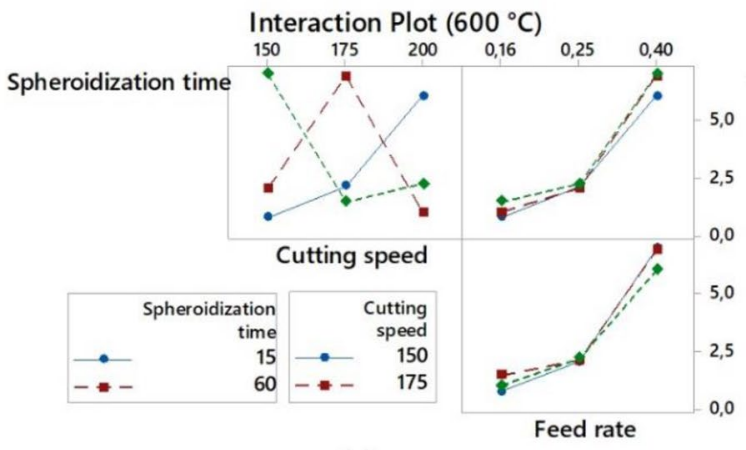

(a)

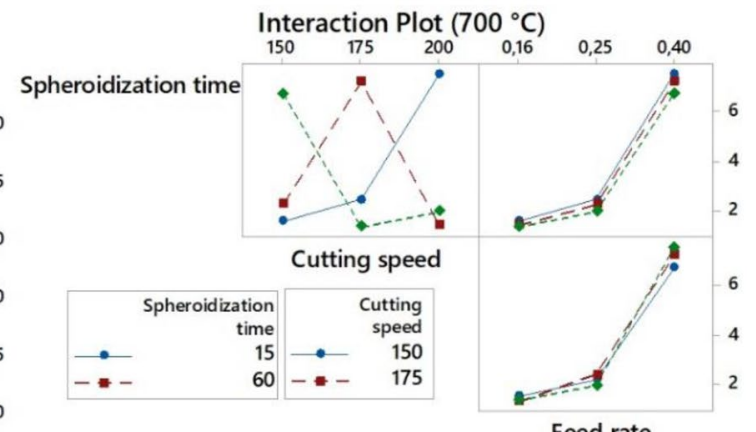

(b)

Fig. 6 Interactions of the parameters with effects on the surface roughness $\mathbf{a} 600^{\circ} \mathrm{C} \mathbf{b} 700^{\circ} \mathrm{C}$

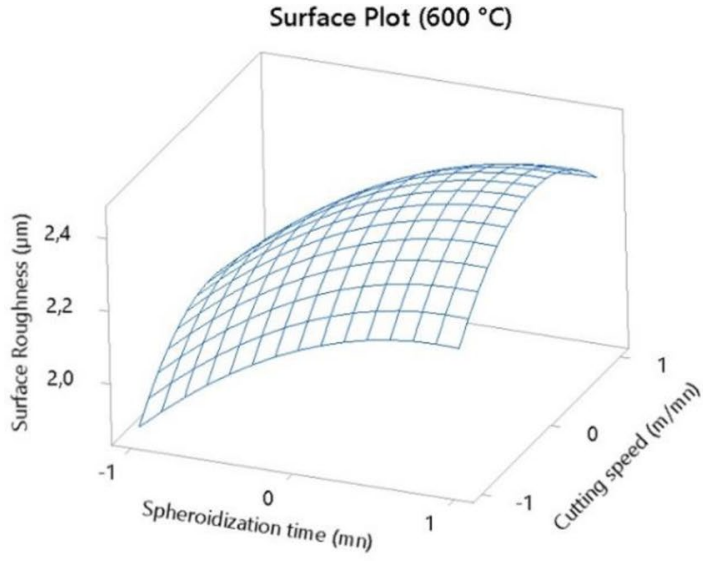

(a)

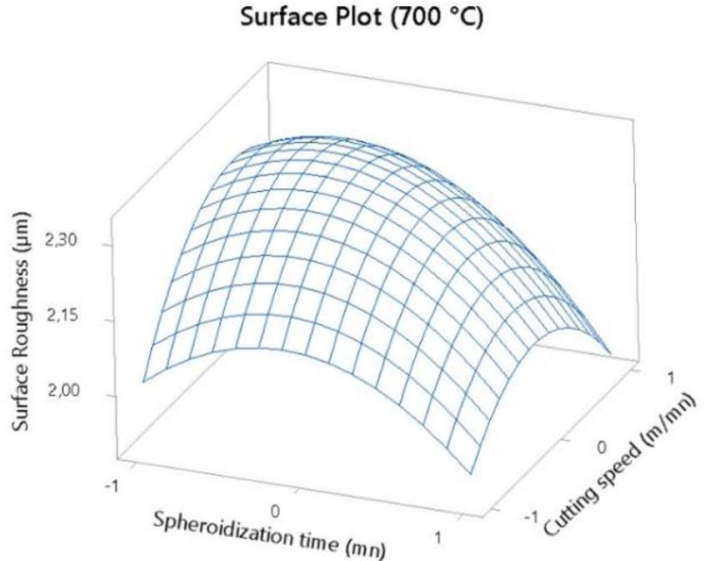

(b)

Fig. 7 Relationship of surface roughness with spheroidization time and cutting speed $\mathbf{a} 600^{\circ} \mathrm{C} \mathbf{b} 700^{\circ} \mathrm{C}$ 


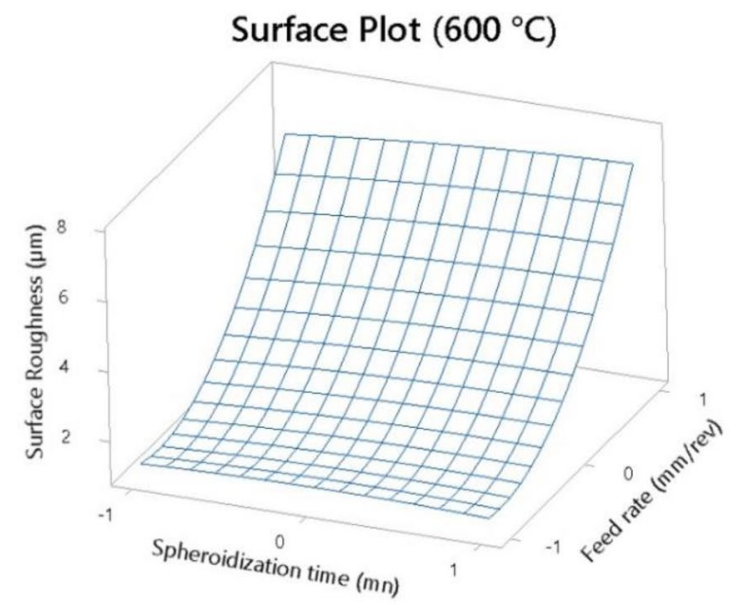

(a)

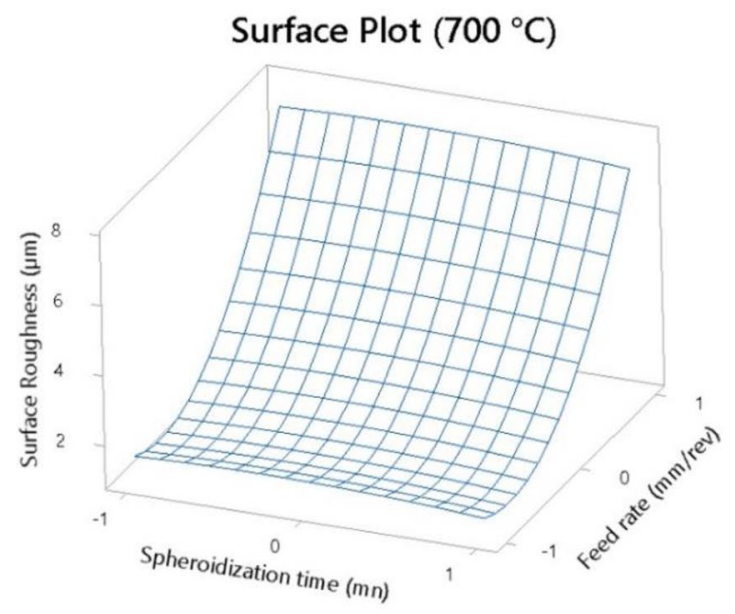

(b)

Fig. 8 Relationship of surface roughness with spheroidization time and feed rate $\mathbf{a} 600^{\circ} \mathrm{C} \mathbf{b} 700^{\circ} \mathrm{C}$

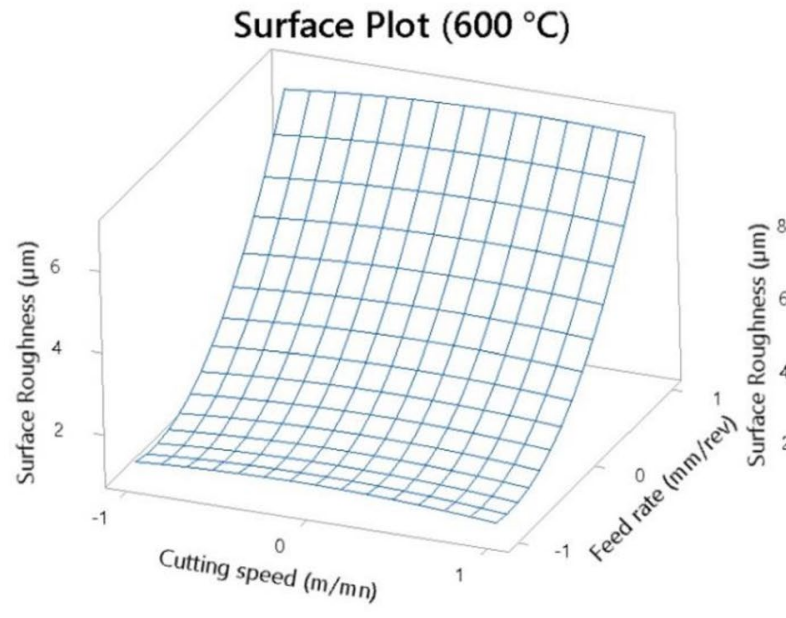

(a)

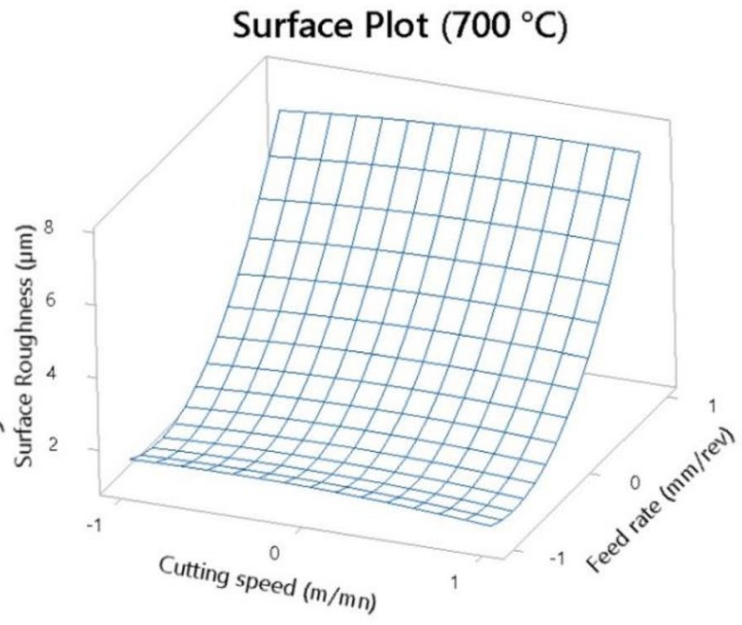

(b)

Fig. 9 Relationship of surface roughness with cutting speed and feed rate $\mathbf{a} 600^{\circ} \mathrm{C}$ b $700{ }^{\circ} \mathrm{C}$

When Fig. 7 is examined, an increase in the surface roughness values may be observed in the experiments at $600{ }^{\circ} \mathrm{C}$ depending on the increase in the spheroidization time and cutting speed parameters. In the experiments carried out at $700{ }^{\circ} \mathrm{C}$, there was no significant effect of spheroidization time. In parallel with the increase in the cutting speed, the surface roughness increased and then it decreased. Similar to the results in RSM, these two parameters did not produce significant results when evaluated in TM. The effect of these two parameters on the experimental results was only about $1 \%$, which prevented them from producing significant results. The effects of spheroidization time and feed rate parameters on the surface roughness are evaluated in Fig. 8.
In terms of surface roughness, when the effect of spheroidization time and feed rate was examined (Fig. 8), the spheroidization time was shown to be ineffective in the experiments conducted at both temperatures. The feed rate alone determined almost the entire effect. Similar to previous analyses, the change in spheroidization temperature did not have any significant effect. Finally, the effects of cutting speed and feed rate parameters on surface roughness were evaluated (Fig. 9).

As seen in Fig. 9, the parameters of cutting speed and feed rate were analyzed. The cutting speed in parallel with what is presented in the previous figure (Fig. 8) did not reveal a significant change for both temperatures $\left(600^{\circ} \mathrm{C}\right.$ and $700^{\circ} \mathrm{C}$ ). All changes in Fig. 8 were shaped according 
to the change in the feed rate parameter. Similar to the result obtained in this study, it has been understood that the feed rate parameter is the most dominant parameter in many different machining studies $[7,14]$.

After the analysis of both models, the ability to predict these models was investigated. Twenty-seven experiments were performed at both $600^{\circ} \mathrm{C}$ and $700{ }^{\circ} \mathrm{C}$. For each temperature, 15 experiments were carried out with RSM and nine experiments were conducted with TM. After these experiments, these two experimental design methods were used to predict all experimental results. The plots showing the results obtained with the methods that were applied are shown in Figs. 10 and 11.

When both plots are examined, it may be seen that both the RSM and TM models produced near-perfect results. At a temperature of $600{ }^{\circ} \mathrm{C}$, the value of 0.9965 $R^{2}$ was reached with RSM. When the same dataset was analyzed with TM, the value of $R^{2}$ was 0.992 . Likewise, for a temperature of $700{ }^{\circ} \mathrm{C}$, the value of 0.9969 was reached with RSM and the value of $0.9964 R^{2}$ was reached with TM. The very high $R^{2}$ values calculated in both methods highlighted that both methods were suitable for solving this engineering problem.

In order to evaluate the methods between each other, the results obtained by using these experimental design methods were compared to the experimental results. For this purpose, a similarity graph showing the similarity ratio of the results is shown in Figs. 12 and 13. In the process of creating the plots, the results obtained by the
Fig. 10 Evaluation of prediction ability of experimental design models at $600{ }^{\circ} \mathrm{C}$
Fig. 11 Evaluation of prediction ability of experimental design models at $700^{\circ} \mathrm{C}$
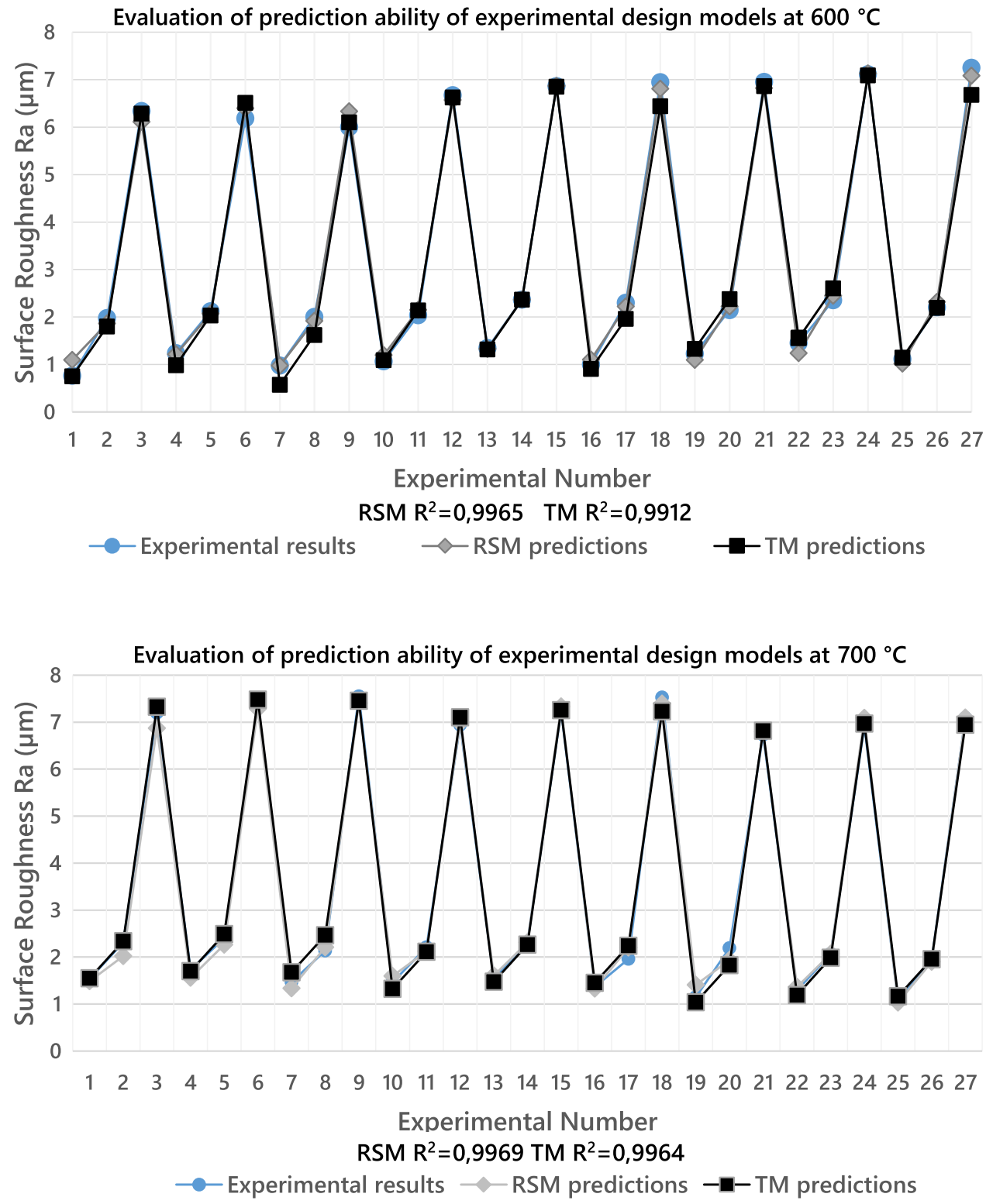
Fig. 12 Evaluation of percentage compatibility of experimental design models at $600^{\circ} \mathrm{C}$ temperature

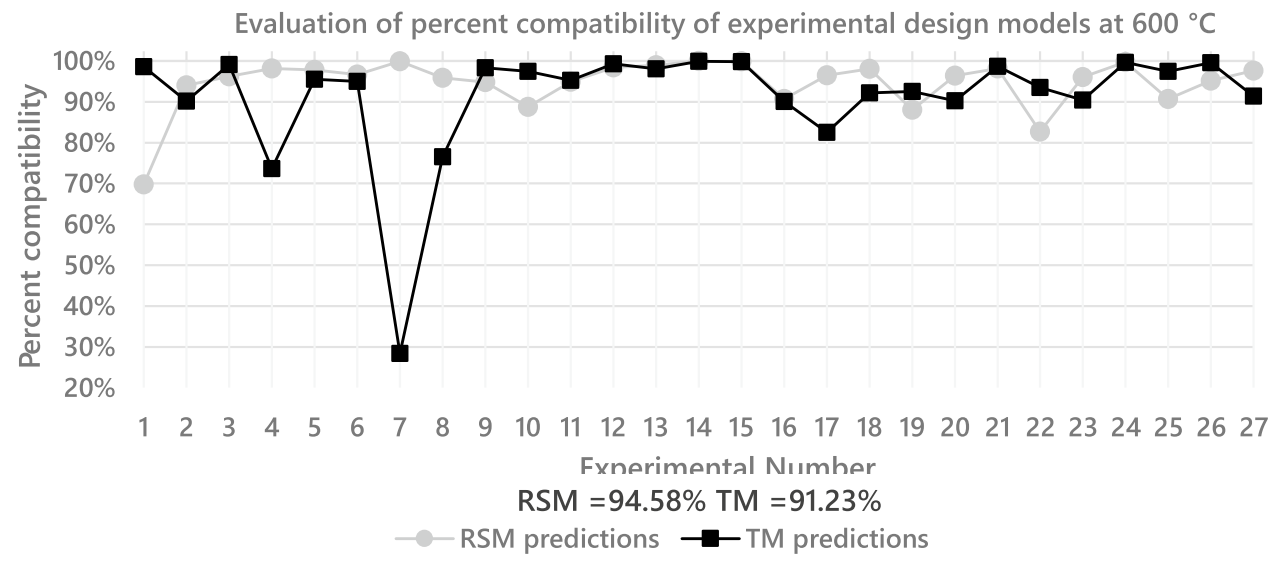

Fig. 13 Evaluation of percentage compatibility of experimental design models at $700{ }^{\circ} \mathrm{C}$ temperature

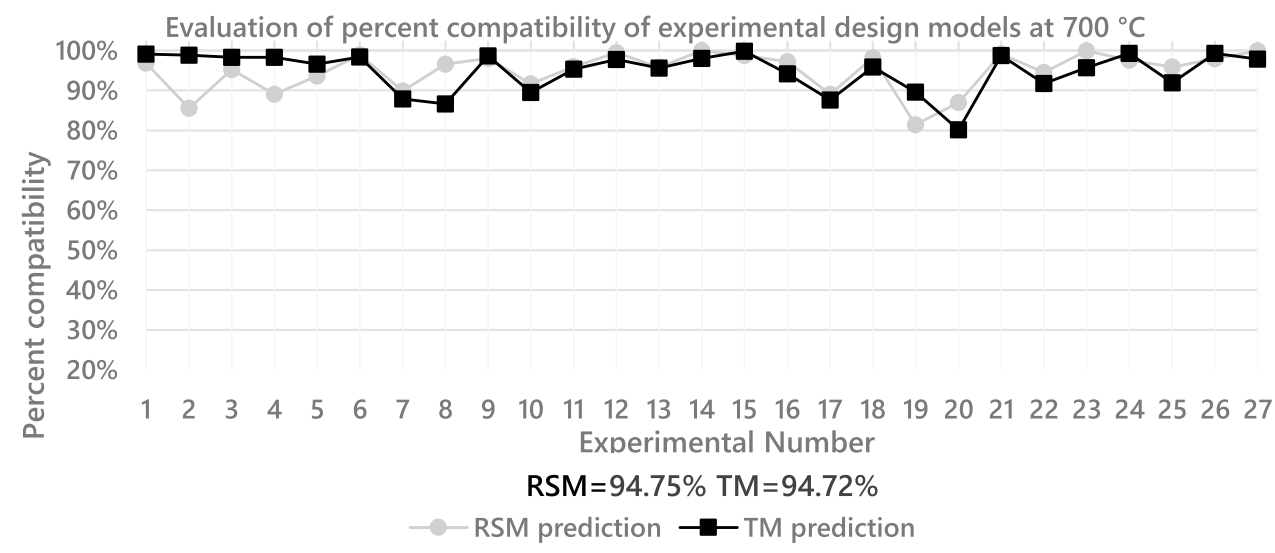

experimental design methods were determined as the percentage of similarity to the actual test results.

In the plot shown in Fig. 12, the results obtained with both the experimental design methods for $600{ }^{\circ} \mathrm{C}$ temperature are compared to the results of the experiment. In both methods, it was observed that the plots differed in terms of similarity percentages while reaching quite high $\mathrm{R}^{2}$ values. Although the similarity percentage values were quite high ( $\mathrm{RSM}=94.58 \%$ and $\mathrm{TM}=91.23 \%)$, it was seen that the percentage similarity rates obtained by the methods differed significantly in the first, fourth, and seventh experiments. In experiment no. 1, the percentage performance of the RSM method (68.78\%) was low. The same test data in the Taguchi method achieved a success ratio of $98.6 \%$. In the fourth and seventh experiments, the percentage performance of TM was low. At this point, especially experiment number 7 was different. The performance of the seventh experiment was $28.4 \%$ when it was evaluated with the Taguchi method and $99.87 \%$ when it was evaluated with the response surface method. It is noteworthy that both of these methods had high $R^{2}$ values. However, they had different predictions. This may have occurred due to deviations in some experimental results due to experimental conditions.
The evaluation made in Fig. 12 was carried out with the same methods in Fig. 13 for the temperature of $700{ }^{\circ} \mathrm{C}$. In Fig. 12, unlike Fig. 12, the performance of the majority of test data exceeds $90 \%$. The mean performance was $94.75 \%$ for RSM and $94.72 \%$ for TM. The incompatibility seen in Fig. 12 was not seen at the $700{ }^{\circ} \mathrm{C}$ temperature in Fig. 13. This may be explained by the fact that the experiments carried out at $700{ }^{\circ} \mathrm{C}$ were affected less by the experimental conditions. Different studies have shown high consistency for both TM (96.8\%- [14], 94\%- [7]) and RSM (90.21\%- [24], 82.5\%- [22], 87.5\%- [23]) in the optimization of machining operations. When these results were evaluated, it was understood that the analyses made with TM obtained the same results as the successful studies in the literature, and the analyses made with the RSM obtained more successful results compared to the studies in the literature.

Both methods could be used effectively to solve this engineering problem. However, unlike the analysis using RSM's 15 experimental data, TM performed the same analysis with only nine experimental data. On the other hand, RSM stood out with its high percentage compliance and more stable structure. 


\section{Conclusions}

This engineering problem, which is based on the analysis of surface roughness values after turning of spheroidized medium-carbon steel materials, was investigated. In this study, the spheroidization time, cutting speed, and feed rate parameters that influence surface roughness values were modeled for both the $600{ }^{\circ} \mathrm{C}$ and the $700^{\circ} \mathrm{C}$ spheroidization temperatures. The response surface method and Taguchi method were used as the modeling methods. At the end of the analysis with these methods, the following inferences could be made;

- It was seen that the main parameters affecting the surface roughness values, the feed rate, spheroidization time, and cutting speed did not have a significant effect.

- At both the $600{ }^{\circ} \mathrm{C}$ and $700^{\circ} \mathrm{C}$ temperatures, the same results were obtained, and it was understood that the effect of spheroidization temperature was not significant.

- In all experimental design methods, the $R^{2}$ values above 0.99 showed that both methods were effective in solving this problem.

- In the RSM and TM experimental design methods that were used, it was seen that the percentage similarity rates were higher than $90 \%$ in similarity to the higher $R^{2}$ values.

- Despite the high percentage of similarity rates at $600{ }^{\circ} \mathrm{C}$, both experimental methods showed that some estimates produce low percentage convergence.

- In particular, the Taguchi method was estimated at $28.4 \%$ with a very low percentage of similarity despite estimates of high percentage adaptation. Similarly, the estimates made with the RSM method were also relatively low (68.78\%).

- For both temperatures $\left(600^{\circ} \mathrm{C}, 700^{\circ} \mathrm{C}\right), \mathrm{RSM}$ used 15 experimental data, while TM performed the same analysis with only nine experimental data. Additionally, considering the percentage similarity ratio, it was understood that the RSM method produced more stable results.

\section{Compliance with ethical standards}

Conflict of interest The authors declare no conflict of interest.

\section{References}

1. Davim JP (2001) A note on the determination of optimal cutting conditions for surface finish obtained in turning using design of experiments. J Mater Process Technol 116(2-3):305-308

2. Leo Kumar SP, Avinash D (2019) Influence of cutting conditions on surface characteristics in micro-milling of Ti-6Al-7Nb alloy. Mater Manuf Process 34(16):1783-1791. https://doi. org/10.1080/10426914.2019.1669803

3. Thomas MBY, Youssef AY, Masounave J (1996) Effect of tool vibrations on surface roughness during lathe dry turning process. Comput Ind Eng 31(3-4):637-644

4. Jang JL, Tarng YS (1999) A study of the active vibration control of a cutting tool. J Mater Process Technol 95:1-3

5. Abouelatta OB, Madl J (2001) Surface roughness prediction based on cutting parameters and tool vibrations in turning operations. J Mater Process Technol 118:1-3

6. Ozturk S (2016) Application of the taguchi method for surface roughness predictions in the turning process. Mater Test 58(9):782-787

7. KıvakT (2014) Optimization of surface roughness and flank wear using the taguchi method in milling of Hadfield steel with PVD and CVD coated inserts. Measurement 50:19-28. https://doi. org/10.1016/j.measurement.2013.12.017

8. Ribeiro João Eduardo CMB, Hernâni L (2017) Optimization of machining parameters to improve the surface quality. Procedia Struct Integr 5:355-362

9. Awopetu OOFPK, Olorunfemi GE (2017) Investigating the surface roughness of AISI 1020 steel machined using TiN coated cemented carbide tool. Int J Adv Eng Technol 1(5):8-13

10. Verma J, Agrawal P, Bajpai L (2012) Turning parameter optimization for surface roughness of ASTM A242 Type- 1 alloys steel by taguchi method. Int J Adv Eng Technol 3(1):255-261

11. Thamizhmanii S, Saparudin S, Hasan S (2007) Analyses of surface roughness by turning process using taguchi method. J Achiev Mater Manuf Eng 20(1-2):503-506

12. Palanikumar K (2016) Cutting parameters optimization for surface roughness in machining of gfrp composites using taguchi's method. J Reinf Plast Compos 25(16):1739-1751. https://doi. org/10.1177/0731684406068445

13. Salvi SB, Deshmukh RR, Deshmukh SD (2013) Analysis of surface roughness in hard turning by using taguchi method. Int J Eng Sci Technol (IJEST) 5:2

14. Sarikaya M (2015) Optimization of the surface roughness by applying the taguchi technique for the turning of stainless steel under cooling conditions. Mater tehnol 49(6):941-948. https:// doi.org/10.17222/mit.2014.282

15. Sahoo $P$ (2011) Optimization of turning parameters for surface roughness using RSM and GA. Adv Prod Eng Manag 6(3):197-208

16. Muñoz-Escalona P, Maropoulos PG (2009) Artificial neural networks for surface roughness prediction when face milling $\mathrm{Al}$ 7075-T7351. J Mater Eng Perform 19(2):185-193. https://doi. org/10.1007/s11665-009-9452-4

17. Basmacı G (2018) Optimisation and influence of cutting parameters on surface roughness during turning of astm b574 (hastelloy c-22) using a hybrid of taguchi and rsm methods Sakarya University. J Sci 22:761-771. https://doi.org/10.16984/saufe nbilder.353379

18. Ekici EUG, Kıvak T (2014) Evaluation of the effects of cutting parameters on the surface roughness during the turning of hadfield steel with response surface methodology. Uludağ Univ J Fac Eng 19(2):19-28

19. Izelu CO, Eze SC, Samuel OD (2016) Modeling and optimization of surface roughness and machining induced vibration in $41 \mathrm{cr} 4$ 
alloy structural steel turning operation using design of experiment. Int J Eng Sci 5(7):34-44

20. Kumar R, Chauhan $S$ (2015) Study on surface roughness measurement for turning of $\mathrm{Al} \mathrm{7075/10/SiCp} \mathrm{and} \mathrm{Al} 7075$ hybrid composites by using response surface methodology (RSM) and artificial neural networking (ANN). Measurement 65:166-180. https://doi.org/10.1016/j.measurement.2015.01.003

21. Kuntoğlu M, Sağlam H (2020) Investigation of signal behaviors for sensor fusion with tool condition monitoring system in turning. Measurement. https://doi.org/10.1016/j.measuremen t.2020.108582

22. Kuntoglu M, Aslan A, Saglam H, Pimenov DY, Giasin K, Mikolajczyk T (2020) Optimization and analysis of surface roughness, flank wear and 5 different sensorial data via tool condition monitoring system in turning of AISI 5140. Sensors (Basel) 20:16. https://doi.org/10.3390/s20164377

23. Aslan A (2020) Optimization and analysis of process parameters for flank wear, cutting forces and vibration in turning of AISI 5140: a comprehensive study. Measurement 163:107959. https ://doi.org/10.1016/j.measurement.2020.107959
24. Touggui Y, Belhadi S, Mechraoui S-E, Uysal A, Yallese MA, Temmar M (2020) Multi-objective optimization of turning parameters for targeting surface roughness and maximizing material removal rate in dry turning of AISI L with PVD-coated cermet insert. SN Appl Sci 2:8. https://doi.org/10.1007/s42452-020-3167-4

25. Vinayagamoorthy $R$ (2017) Parametric optimization studies on drilling of sandwich composites using the box-behnken design. Mater Manuf Process 32(6):645-653. https://doi. org/10.1080/10426914.2016.1232811

26. Goud V, Ramasamy A, Das A, Kalyanasundaram D (2019) BoxBehnken technique based multi-parametric optimization of electrostatic spray coating in the manufacturing of thermoplastic composites. Mater Manuf Process 34(14):1638-1645. https:// doi.org/10.1080/10426914.2019.1666991

Publisher's Note Springer Nature remains neutral with regard to jurisdictional claims in published maps and institutional affiliations. 